\title{
Electrical Impedance Spectroscopy Using Single Wall Carbon Nanotubes Carboxlic Acid Functionalized: Detection of Copper in Tabuk-Kingdom of Saudi Arabia Water
}

Saloua Helali ${ }^{*}$, Nadra Bohli ${ }^{2}$, Hala Mohamed Abo Mostafa ${ }^{1}$, Houda ben zina ${ }^{1}$, Omar A Al-Hartomy ${ }^{3}$ and Adnane Abdelghani ${ }^{2}$

${ }^{1}$ Department of Physics, Faculty of Science, University of Tabuk, Tabuk P.O.Box 741, Kingdom of Saudi Arabia

${ }^{2}$ Nanotechnology Group, National Institute of Applied Science and Technology, Bp676, Centre Urbain Nord, 1080 Charguia Cedex, Tunisia

${ }^{3}$ Department of Physics, Faculty of Science, King Abdul Aziz University, Jeddah 21589, Kingdom of Saudi Arabia

\begin{abstract}
Copper $(\mathrm{Cu})$ is an essential element in mammalian nutrition. Since both copper deficiency and copper excess produce adverse health effects, so it is important to develop simple, sensitive and accurate methods for their detection in environment and food. In this study, the absorption of the copper ion in single wall carbon nanotubes carboxylic acid functionalized (SWCNTCOOH) was studied in buffer saline (PBS) and in Tabuk, kingdom of Saudi Arabia water. The gold electrode is functionalized with the self-assembled monolayer technique. The modified surface is activated with $\mathrm{EDC} / \mathrm{NHS}$ for SWCNT-COOH immobilization. Each grafted layer on the gold electrode was characterized with cyclic voltammetry, impedance spectroscopy and Fourrier Transform Infra-Red spectroscopy (FTIR). The high insulating properties of the acidic thiol monolayer has been proved by cyclic voltammetry and impedance spectroscopy. The increases in DC current and the decrease in impedance confirm the conducting properties of the SWCNT-COOH layer. The development of sensor for copper detection was observed with the impedance spectroscopy. During impedance measurements, the charge transfer resistance increased significantly after absorption the copper in both buffer. The response of the developed sensor was very sensitive in the range of $10-300 \mathrm{ng} / \mathrm{ml}$. The result show that the signal in Tabuk water is four time large relative to the signal in PBS.
\end{abstract}

Keywords: Single wall carbon nanotubes; Copper absorption; Sensors; Impedance spectroscopy; Cyclic voltammetry; Tabuk water

\section{Introduction}

Heavy metals in water have been a major preoccupation for many years because of their toxicity towards aquatic-life, human beings and the environment. They are non-biodegradable, and can enter into the food chain by accumulation in animals and plants, or respiratory tract and their effects may be very serious [1,2]. Heavy metals can cause a disruption of function of the kidneys, bones, central nervous system, and hematopoietic system and have adverse biochemical, histological, neuropsychological and reproductive effects. Several processes have been used and developed over the years to remove metal ions, such as chemical precipitation, reverse osmosis, electrolytic recovery, ion exchange or adsorption [3].

Copper and its compounds are widely used in many industries and there are many potential sources of copper pollution. Copper contamination in water streams occurs mainly from metal cleaning and plating bath, fertilizer, refineries, paper and pulp, and wood preservatives $[4,5]$. Copper is an essential nutrient mineral that are required to a varying degree in plants and animals, but when present in elevated bioavailable concentrations, these elements can become toxic. Due to this concern, there has been a push to remove heavy metals from road runoff. According to the Safe Drinking Water Act the permissible limit of copper in drinking water is $1.3 \mathrm{mg} / \mathrm{dm}^{3}$ [6]

Smart materials developed using nanotechnology has the potential to improve the way we generate and measure motion in devices. These highly advanced and revolutionary technologies are focused on the study and application of materials based on individual particles having a size in the order of nano and/or micrometers [7,8]. Carbon nanotubes are a new type of materials from carbon family have a coaxial cylindrical form, composed of graphene sheets within nanometer size in diameter and micrometer size in length [9]. These materials are classified to single-walled (SWCNTs) and multiwalled (MWCNTs) carbon nanotubes. Individual carbon nanotubes (CNTs) have been shown to have high modulus $(0.7 \mathrm{TPa})$ and high strength $(30 \mathrm{GPa})$ while also displaying high electrical $(10-30 \mathrm{kS} / \mathrm{cm})$ and thermal $(2000$ $\mathrm{W} / \mathrm{mK}$ ) conductivities [10]. Structural and electrical characteristics of CNTs include a large surface area, piezoresistivity and electrochemical properties that make them an interest in the building of advanced sensors and actuators $[9,11,12]$. Strong adsorption capacity is the main reason for using these materials in analytical chemistry; especially in removing environmental pollutants such as phenols [13], heavy metals [14], pesticide [15], organo phosphorus compounds [16], and lead [17].

A number of works benefiting from all this intrinsic advantages of carbon nanotubes have used electrochemical impedance spectroscopy (EIS) to characterize the electrochemical behavior of CNTs [18-20]. Electric impedance spectroscopy is a sensitive technique, which monitors the electrical response of the system studied after application of a periodic small amplitude ac signal. Analysis of the system response provides information concerning the electrical behaviour of the interface and interaction occurring on it [20-26].

This study is motivated by the current researches in the field of adsorption of heavy metal ions using functionalized carbon nanotubes.

*Corresponding author: Saloua M Younis Helali, Department of Physics, Faculty of Science, University of Tabuk, Tabuk P.O.Box 741, Kingdom of Saudi Arabia, Tel: +216 71703 829; E-mail: s.helali@ut.edu.sa

Received August 24, 2016; Accepted August 27, 2016; Published August 31 2016

Citation: Helali S, Bohli N, Mostafa HMA, ben Zina H, Al-Hartomy OA, et al. (2016) Electrical Impedance Spectroscopy Using Single Wall Carbon Nanotubes Carboxlic Acid Functionalized: Detection of Copper in Tabuk-Kingdom of Saudi Arabia Water. J Nanomed Nanotechnol 7: 396. doi: 10.4172/2157-7439.1000396

Copyright: (๑ 2016 Helali S, et al. This is an open-access article distributed under the terms of the Creative Commons Attribution License, which permits unrestricted use, distribution, and reproduction in any medium, provided the original author and source are credited. 
Citation: Helali S, Bohli N, Mostafa HMA, ben Zina H, Al-Hartomy OA, et al. (2016) Electrical Impedance Spectroscopy Using Single Wall Carbon Nanotubes Carboxlic Acid Functionalized: Detection of Copper in Tabuk-Kingdom of Saudi Arabia Water. J Nanomed Nanotechnol 7: 396. doi: 10.4172/2157-7439.1000396

Page 2 of 8

In this work, we used carbon nanotube, single-walled, carboxylic acid functionalized for copper detection. The stability and the molecular structure of the single-walled carbon nanotube were characterized with cyclic voltammetry, impedance spectroscopy and Fourrier Transform Infra-Red spectroscopy. It shows a higher conductivity and a good stability in water interface. For carbon nanotubes immobilization, the gold electrode was activated over night with thiol-acid (16 carbons). An activation procedure was achieved with EDC/NHS for carbon nanotube carboxylic acid functionalized immobilization. The development of sensors for copper detection was observed with the impedance spectroscopy techniques. This method could be used to determine total copper concentration in the range $10 \mathrm{ng} / \mathrm{ml}-300 \mathrm{ng} / \mathrm{ml}$. The response of the developed sensors was reproducible with higher stability. The cyclic voltammetry and impedance spectroscopy techniques were also applied to monitor copper detection in Tabuk water samples.

\section{Materials and Methods}

\section{Reagents}

Single-walled carbon nanotubes carboxylic acid functionalized were obtained from Sigma-Aldrich. Nanotubes were length range from $0.5 \mu \mathrm{m}$ to $1.5 \mu \mathrm{m}$ and their diameters ranged from $4 \mathrm{~nm}$ to $5 \mathrm{~nm}$. All other materials, including 16-mercapto-hexadecanoic acid (MHDA), 1-ethyl-3-(3-(dime-thylamino)-propyl)carbodiimide (EDC), and N-hydroxy succinimide (NHS) was purchased from Sigma-Aldrich.

The buffer solution used for all experiments was phosphate buffered saline (PBS) containing $140 \mathrm{mM} \mathrm{NaCl}, 2.7 \mathrm{mM} \mathrm{KCl}, 0.1 \mathrm{mM}$ $\mathrm{Na}_{2} \mathrm{HPO}_{4}, 1.8 \mathrm{mM} \mathrm{KH} \mathrm{PO}_{4}, \mathrm{pH}=7$ and the redox couple at a $5 \mathrm{mM}$ concentration. All reagents were of analytical grade and ultrapure water (resistance $18.2 \mathrm{M} \Omega \cdot \mathrm{cm}^{-1}$ ) produced by a MilliporeMilli-Q system was used.

\section{Gold cleaning}

The gold electrodes $(1 \mathrm{~cm} \times 1 \mathrm{~cm})$ were fabricated at the National Center of Microelectronics of Barcelona (Spain). Evaporated gold ( $\sim 300 \mathrm{~nm}$ thickness) was deposited on silicon, using a titanium under layer ( $\sim 30 \mathrm{~nm}$ thickness) as substrate. Before modification, the gold electrodes were cleaned in acetone solution for $10 \mathrm{~min}$ with ultrasonic bath. After that, they were dried under a nitrogen flow and then dipped for 10 min into "piranha solution" 7:3 (v/v) 96\% H2SO4/30\% $\mathrm{H} 2 \mathrm{O} 2$. After each pre-treatment, the gold substrates were rinsed successively with Milli-Q filtered water and ethanol and then dried with a stream of $\mathrm{N}_{2}$.

\section{Self-assembled monolayer}

After cleaning, the gold electrodes were immediately immersed in an ethanol solution of $1 \mathrm{mM} 16$-mercaptohexadecanoic acid for $21 \mathrm{~h}$ at room temperature. The gold substrates were then 4 to 5 times rinsed with ethanol in order to remove the non-bonded thiol and dried under a $\mathrm{N}_{2}$ flow.

\section{Carboxyl SWCNTs immobilization}

To convert the terminal carboxylic groups to an active NHS ester, the thiol-modified electrodes were treated with $0.4 \mathrm{mM}$ EDC-0.1 $\mathrm{mM}$ NHS for $45 \mathrm{~min}$. After rinsing the gold electrodes with water, $0.3 \mathrm{mg} / \mathrm{ml}$ of SWCNTCOOH in DMF solvent was dropped onto the gold surface and incubated at room temperature for $1 \mathrm{~h}$. The excess of SWCNTCOOH were removed by rinsing with DMF. Figure 1 shows

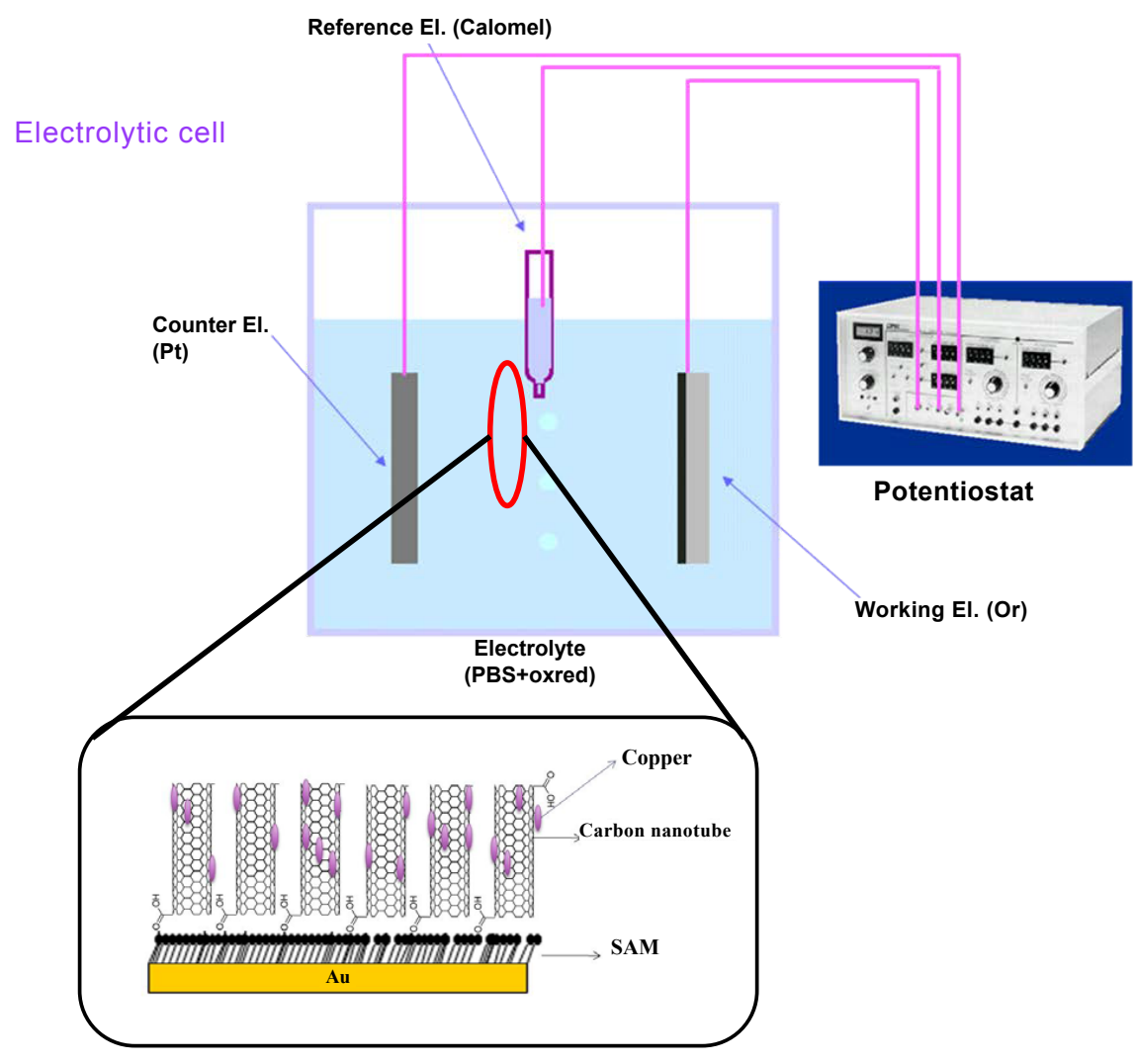

Figure 1: Schematic illustration of general principle of electrochemical sensing of copper ions. 
Citation: Helali S, Bohli N, Mostafa HMA, ben Zina H, Al-Hartomy OA, et al. (2016) Electrical Impedance Spectroscopy Using Single Wall Carbon Nanotubes Carboxlic Acid Functionalized: Detection of Copper in Tabuk-Kingdom of Saudi Arabia Water. J Nanomed Nanotechnol 7: 396. doi: 10.4172/2157-7439.1000396

Page 3 of 8

the schematic representation of the fabrication process of the multilayer structure of the sensor.

\section{Copper absorption}

Aqueous solutions containing $\mathrm{Cu}^{2+}$ cations of concentration $(10$, $50,100,150$ and $300 \mathrm{ng} / \mathrm{ml}$ ) were prepared from hydrated copper sulfate $\left(\mathrm{CuSO}_{4}, 5 \mathrm{H}_{2} \mathrm{O}\right)$. The electrode modified with $\mathrm{SWCNTCOOH}$ was dipped into an electrochemical cell containing $5 \mathrm{ml}$ of PBS redox. Different volumes of copper corresponding to different concentrations of copper in the cell were added into electrochemical cell at room temperature. The copper absorption were monitored by impedance spectroscopy in PBS redox.

\section{Adsorption mechanism of copper}

The mechanisms of heavy metal ion adsorption on CNTs are very complicated and appear attributable to physical adsorption, electrostatic attraction, precipitation and chemical interaction between the heavy metal ions and the surface functional groups of CNTs. Among all these, chemical interaction between heavy metal ions and the surface functional groups of CNTs is the major adsorption mechanism (Figure 2). Hydrogen atoms from carboxylic of CNTs exchange with metal ions which results in drop in $\mathrm{pH}$ of solution.

\section{Electrochemical Set-Up}

\section{Cyclic voltammetry}

Cyclic voltammetry was performed at room temperature in a conventional voltammetric cell with a three electrode configuration using Autolab 302 impedance anlayzer (Eco- chemie, Netherland). The gold electrode $\left(0.16 \mathrm{~cm}^{2}\right)$ was used as working electrode, platinum $\left(1 \mathrm{~cm}^{2}\right)$ and calomel electrodes were used as counter and reference electrodes, respectively. All the electrochemical were performed in the presence of a $5 \mathrm{mM} \mathrm{K}_{3}\left[\mathrm{Fe}(\mathrm{CN})_{6}\right] / \mathrm{K}_{4}\left[\mathrm{Fe}(\mathrm{CN})_{6}\right](1: 1)$ mixture as redox probe in $\mathrm{PBS}$ at $\mathrm{pH} 7.0$ and were carried out at room temperature and in a Faraday cage.

\section{Impedance spectroscopy}

The impedance analysis was performed with the Autolab 302 $\mathrm{N}$ impedance analyzer (Eco-Chemie, Netherland) in the frequency range $0.05 \mathrm{~Hz}-100 \mathrm{kHz}$, using a modulation voltage of $10 \mathrm{mV}$. During measurements the potential was kept at $200 \mathrm{mV}$. The Zview modeling programme (Scribrer and associates, Charlottesville, VA) was used to analyse impedance data.
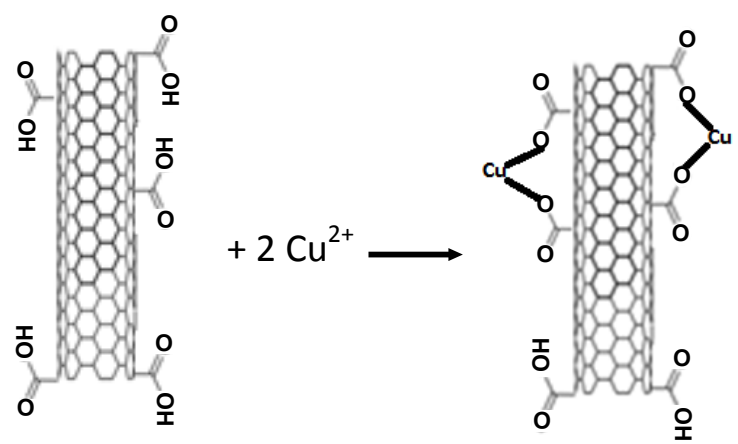

$+4 \mathrm{H}^{+}$

Figure 2: Schematic diagram of the mechanism for sorption of copper ions onto CNT surface.

\section{Fourier transform infra-red spectroscopy}

To confirm the immobilization SWCNT-COOH on gold surface, we used an FTIR spectrometer (BRUKER-IFS-66V/S) equipped with a Germanium $(\mathrm{Ge})$ monoreflection prism with a fixed incident angle of $45^{\circ}$ and a DTGS detector. All spectra were recorded at $4 \mathrm{~cm}^{-1}$ resolution with 28 scans, from $400 \mathrm{~cm}^{-1}$ to $4000 \mathrm{~cm}^{-1}$. Our method consisted on recording the spectrum of the cleaned gold substrate and then the gold substrate with SAM and then SWCNT-COOH film. The spectrum of the cleaned gold electrode served as a reference.

\section{Results and Discussions}

\section{Characterization of deposited single-walled carbon nanotubes carboxylic acid on gold labeled self-assembled monolayers in PBS buffer}

Surface modification of gold: Self-assemblies of organic molecules have been most extensively studied because of their stability, well-packed structure and versatility. One of the most widely-used systems in the molecular self-assembled method is the chemisorption of sulfur derivatives (thiols) on a gold surface. Due to this interaction, SAMs of thioctic acid can be successfully formed through the oxidation of the linkage sulphur and hydrogen with the gold surface and the reduction of hydrogen at ambient conditions. The stability of the bonding over a wide range of applied potentials makes this system suitable for electrochemical purposes [22,27]. The thiol is chemisorbed on the gold electrode and it is used as the base interface for the deposition of different layers. To convert the terminal carboxylic groups of the arrayed acids to active NHS esters, the thiolmodified electrodes were treated with EDC-NHS, which allows it to interact with carboxylic groups in SWCNTCOOH layer. By analyzing the impedance of the SWCNTCOOH /SAM/gold structure, in the frequency range from $0.05 \mathrm{~Hz}$ to $100 \mathrm{KHz}$, the electrical properties of the attached layer can be determined in terms of its resistive and capacitive properties.

Cyclic voltammetry: Cyclic voltammetry is an electrochemical technique which can be used to study the kinetic of redox reactions of materials, their insulating and conducting properties. Figure 3 displays cyclic voltammograms of the (a) bare gold, (b) SAM/Au, and

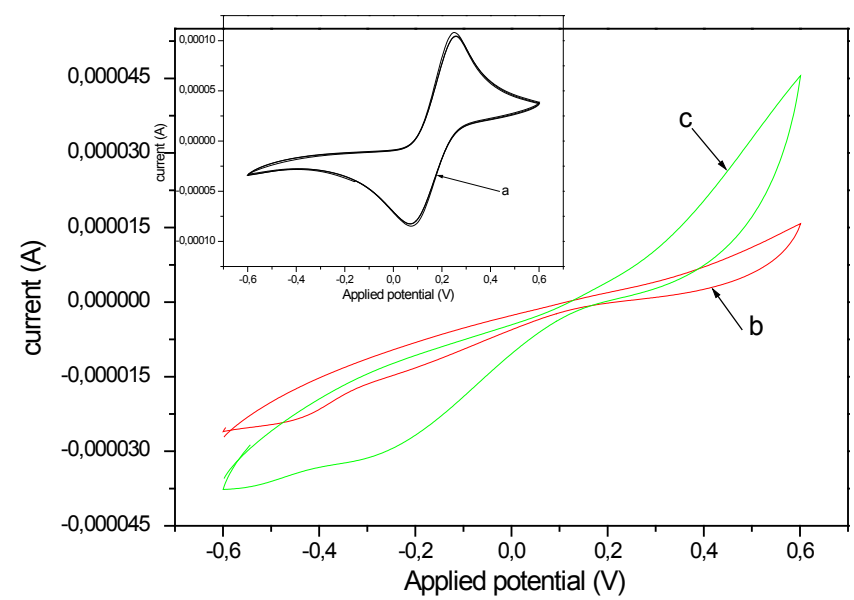

Figure 3: Cyclic voltammograms (CVs) with $100 \mathrm{mVS}^{-1}$ scan rate in PBS with $5 \mathrm{mM} \mathrm{FE}(\mathrm{CN})^{-4 / 3}$ solution, after different steps of modification: (a) bare gold electrode, (b) SAM modified gold electrode (c) Cyclic voltammograms of the gold electrode after SWCNTCOOH deposition. 
Citation: Helali S, Bohli N, Mostafa HMA, ben Zina H, Al-Hartomy OA, et al. (2016) Electrical Impedance Spectroscopy Using Single Wall Carbon Nanotubes Carboxlic Acid Functionalized: Detection of Copper in Tabuk-Kingdom of Saudi Arabia Water. J Nanomed Nanotechnol 7: 396. doi: 10.4172/2157-7439.1000396

Page 4 of 8

(c) SWCNTCOOH/SAM/Au electrode. All voltammograms were cycled five times in order to verify the stability of the signal. Cyclic voltammograms of the gold electrode (Figure 3a) shows a reversible wave which is the typical behavior of gold surface in the presence of the redox couple. As is shown in Figure 3a, the cyclic voltammogram defines the characteristics of a diffusion controlled redox process observed at the cleaned bare gold electrode.

To assess the electrochemical properties of the SAM, cyclic voltammetry was applied. As can be seen in Figure 3b, the two current peaks corresponding to $\mathrm{Fe}(\mathrm{CN})_{6}^{4-}$ oxidation and $\mathrm{Fe}(\mathrm{CN})_{6}^{4-}$ reduction have been disappeared after deposition self-assembled monolayer. The electron transfer kinetics of $\mathrm{Fe}(\mathrm{CN})_{6}^{4-} / \mathrm{Fe}(\mathrm{CN})_{6}^{3-}$ were therefore perturbed and almost all the faradic current was blocked. This confirms that materials (MHDA) were successfully deposited and assembled onto the gold surface to form high insulating properties of the thin layer of thiol to prevent the oxydo-reduction of the gold surface. After modification of the gold surface with SWCNTCOOH, the DC current increases due to the conducting properties of the SWCNTCOOH layer (Figure 3c).The success immobilization of single carbon nanotube fonctionnalized by $\mathrm{COOH}$ layer was confirmed with the current increase.

FTIR: The infrared absorption spectra of thiol monolayer and after immobilization of SWCNTCOOH between 400 and $4000 \mathrm{~cm}^{-1}$ are illustrated in Figure 4.

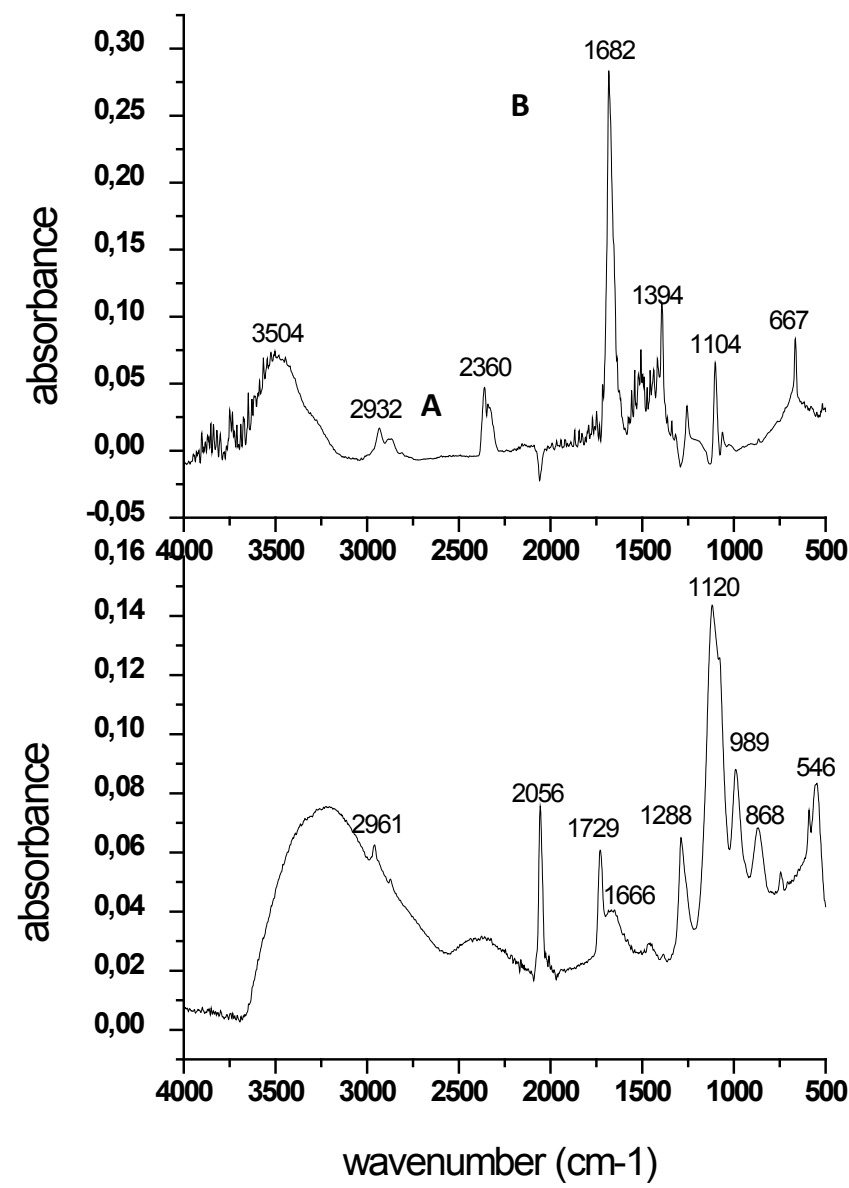

Figure 4: Infrared absorption spectra of gold electrode with (A) SAM layer and (B) after immobilization of single wall carbon nanotubes carboxylic acid fonctionnalized between $400-4000 \mathrm{~cm}^{-1}$.
Figure 4a shows the FTIR spectrum of the SAM layer. The formation of a covalent gold-sulfur bond has been proven by the presence of the large band in the range of 500 to $750 \mathrm{~cm}^{-1}$. This large band is assigned to stretch the mode of C-S groups. The bands at 868 and $989 \mathrm{~cm}^{-1}$ is associated with alkene sp ${ }^{2} \mathrm{C}-\mathrm{H}$ bend. The peak at $1729 \mathrm{~cm}^{-1}$ is due to $\mathrm{C}=\mathrm{O}$ stretching vibration of carboxylic group [28]. The peaks in the $2800-3050 \mathrm{~cm}^{-1}$ region are characteristic of $\mathrm{C}-\mathrm{H}$ stretches. This is assigned to the vibration mode of alkyl thiol chains. The broad band in the $3100-3600 \mathrm{~cm}^{-1}$ is characteristic of acid $\mathrm{O}-\mathrm{H}$ stretches.

In the FTIR spectrum of SWCNT-COOH (Figure 4b), two main bands at $2932 \mathrm{~cm}^{-1}$ and $2360 \mathrm{~cm}^{-1}$ are clearly observed in the high frequency region. These are assigned to the symmetric mode and the antisymmetric mode of $\mathrm{CH} 2$ respectively. The strong absorption peak at $1104 \mathrm{~cm}^{-1}$ is associated with the SWCNT has defects or residual amorphous carbon impurities or both. The spectra shows weak peak at $667 \mathrm{~cm}^{-1}$ for chiral nanotubes. The band at $1683 \mathrm{~cm}^{-1}$ is assigned to C-C stretch vibration of the atoms attached to functional group. Finally the hydroxyl stretching vibrations are generally observed in the region around $3500 \mathrm{~cm}^{-1}$. This peak is broader and its intensity is higher than that of a free $\mathrm{O}-\mathrm{H}$ vibration $[29,30]$. This is confirming the deposition of SWCNTs on gold surface.

\section{Impedance measurement}

Principles of EIS measurements: Electrochemical impedance spectroscopy is a relatively new technique for characterising materials and surface interfaces that has emerged with the development of instruments able to measure impedance as a function of frequency in the $0.5-10^{5} \mathrm{~Hz}$ range. The fundamental approach of all impedance methods is to apply a small amplitude sinusoidal excitation signal to the system under investigation and measure the response.

A low amplitude sinewave $\Delta \mathrm{E} \cdot \sin (\omega \mathrm{t})$ of a particular frequency $\omega$, is superimposed on the DC polarization voltage E0. This results in a current response of a sine wave superimposed on the DC current $\Delta \mathrm{i} \cdot \sin (\omega t+\varphi)$. The current response is shifted with respect to the applied potential. The Taylor series expansion for the current is given by

$$
\Delta i=\left(\frac{d i}{d E}\right)_{E_{0} i_{0}} \Delta E+\frac{1}{2}\left(\frac{d^{2} i}{d E^{2}}\right)_{E_{0 i}} \Delta E^{2}+\ldots
$$

If the magnitude of the perturbing signal $\Delta \mathrm{E}$ is small then the response can be considered linear in first approximation. The higher order terms in the Taylor series can be assumed to be negligible.

The impedance of the system can then be calculated using Ohm's law as

$$
Z(\omega)=\frac{E(\omega)}{i(\omega)}
$$

This makes it possible to treat the response theoretically by linearised or otherwise simplified current-potential characteristics.

Interpretation of EIS measurements is usually done by fitting the impedance data to an equivalent electrical circuit which is representative of the physical processes taking place in the system under investigation. To fit the measured spectra to the impedance spectra model using real, rather than ideal elements, we replaced the ideal elements with the constant phase elements (CPE=Z, Eq. (1)) [31,32]:

\section{$\mathrm{Z}=\mathrm{K} \omega^{\alpha}$}

Where $\mathrm{K}$ and $\alpha$ are experimental parameters $(0 \leq \alpha \leq 1)$. Three special cases depending on the $\alpha$ parameter can be considered: if $\alpha \approx 0, Z$ represents an ideal resistance and $\mathrm{k}=\mathrm{R}$; if $\alpha \approx 1$ then $\mathrm{Z}$ corresponds to an 
Citation: Helali S, Bohli N, Mostafa HMA, ben Zina H, Al-Hartomy OA, et al. (2016) Electrical Impedance Spectroscopy Using Single Wall Carbon Nanotubes Carboxlic Acid Functionalized: Detection of Copper in Tabuk-Kingdom of Saudi Arabia Water. J Nanomed Nanotechnol 7: 396. doi: 10.4172/2157-7439.1000396

Page 5 of 8

ideal capacitor where $\mathrm{K}=1 / \mathrm{C}$, and if $\alpha \approx 0.5$ the circuit element is termed the Warburg impedance $(\mathrm{W})$, where $\mathrm{K}=\mathrm{W}$, which is associated with a diffusion process. The a parameter is related to the area of defects and homogeneities in the surface layer $[33,34]$.

Impedance spectroscopy of the gold electrode coated with thiol SAM and SWCNT-COOH: Impedance spectroscopy of the gold electrod (curve a), compared with SAM changed gold electrode (curve b), and with SWCNTCOOH functionalized Au-electrode (curve c) was recorded in the complex plane, a plot of Zim versus Zre which represents the imaginary versus the real part of impedance, respectively (Figure 5). The experimental impedance spectra was recorded at 200 $\mathrm{mV}$ in PBS redox buffer at $\mathrm{pH}=7.2$ in the range of $50 \mathrm{mHz}$ to $100 \mathrm{KHz}$. The impedance spectra can be fitted with computer simulated program using an electric circuit shown in Figure 6.

Therefore it can be analyzed using an equivalent system that consists of a charge transfer resistance (Rct) and a constant phase element (CPE) in parallel, and $\mathrm{Zw}$ is the impedance due to the mass transfer of the redox species to the electrode described by Warburg impedance, associated with diffusive ion transportion and Rs the ohmic resistance in high frequency ranges is the resistance of the electrolyte, the contacts and connections.

It can be seen that the diameter of the semicircle at high frequency increases after the formation of self-assembling monolayer on the gold electrode due to the high insulating properties of the thin layer of thiol. However, the addition of single wall carbon nanotube layer on the electrode surface decreases the diameter of the semicircle. This decrease in impedance confirms the conducting properties of the SWCNTCOOH layer. The value of Rct, were extracted from the computer simulated spectra. They are $94816 \Omega$ and $41702 \Omega$ for the SAM/Au electrode and the SWCNTCOOH/SAM/Au electrode respectively. We can estimate the percentage of covered area $\theta$ of the thiol, which can be described as:

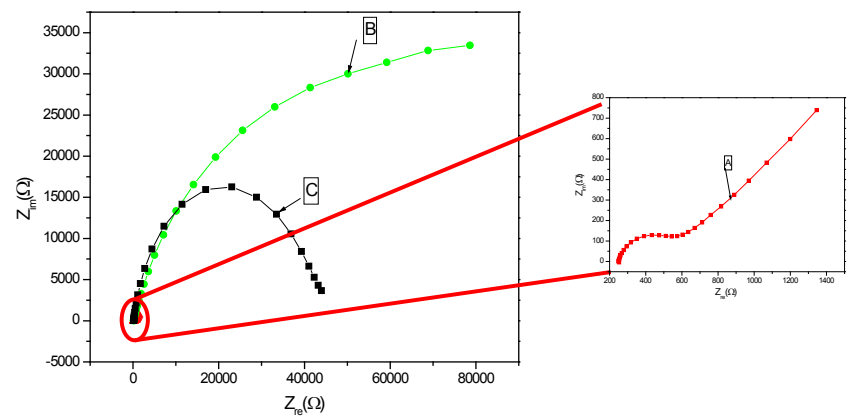

Figure 5: Nyquist diagram (Zre vs. Zim) for impedance measurements corresponding to: (A) bare gold electrode; (B) SAM modified gold and (C) after deposition of SWCNTCOOH. All measurements were performed in PBS $(\mathrm{pH} 7.0)+5 \mathrm{mM} \mathrm{Fe}(\mathrm{CN}) 6-4 /-3$ solution at $200 \mathrm{mV}$. Amplitude of alternating voltage $10 \mathrm{mV}$.

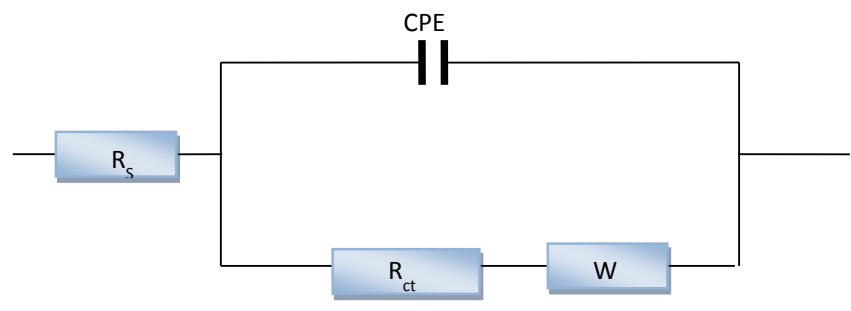

Figure 6: Diagram showing the equivalent circuit for the impedance spectroscopy measurement.

$$
\theta=1-\frac{R_{1} \text { beforethiol deposition }}{R_{2} \text { after thiol deposition }}
$$

We calculate the ratio and we obtain $\theta=99.7 \%$ which prove that the gold was totally covered with thiol layer.

The CPE values extracted from the computer fitting for the thiol/ Au electrode and the SWCNTCOOH /thiol/Au electrode were $4.913 \mu \mathrm{F}$ and $1.358 \mu \mathrm{F}$ respectively. The CPE decreases with the addition of the SWCNT-COOH layer, which proves that the layer thickness increases and that the SWCNTCOOH layer is directly adsorbed onto the thiol without any interpenetration of chains.

\section{Characterization of deposited single-walled carbon nanotubes carboxylic acid on gold labeled self-assembled monolayers in tabuk water}

Copper is an essential nutrient mineral, but it is only needed in small quantities. An excess of one single nutrient mineral can affect so many aspects of both physical and psychological health. The major source of excess copper is water (surface water, groundwater, seawater and drinking-water). In order to prove the presence of copper in tabuk water we repeat all electrochemical measurements in Tabuk water plus redox as buffer. The results will be compared with the results in PBS buffer.

Cyclic voltammetry: Figure 7 shows the cyclic voltammogram of $\mathrm{Fe}(\mathrm{CN})_{6}^{-4 /-3}$ at the gold electrode in tabuk water (red) and in PBS (black). When the interface electrolyte/electrode surface was modified, the electron transfer kinetics of $\mathrm{Fe}(\mathrm{CN})_{6}^{-4 /-3}$ were perturbed. As shown in Figure 7, the change of electrolyte is accompanied by a shift in the peak to peak separation between the cathodic and anodic waves of redox probe. This shows the variance in conductivity between PBS and tabuk water buffer.

Thus, our developed sensor was tested in tabuk water sample. Cyclic voltammograms of the gold electrode, SAM layer and immobilization of SWCNTCOOH were showing in Figure 8. Note that we observe almost the same phenomenon that in PBS. The two current peaks corresponding to $\mathrm{Fe}(\mathrm{CN})_{6}^{4-}$ oxidation and $\mathrm{Fe}(\mathrm{CN})_{6}^{3-}$ reduction have been disappeared after the stepwise assembly of bare gold and selfassembled monolayer but after modification of the gold surface with SWCNT-COOH, the DC current increases due to the conducting

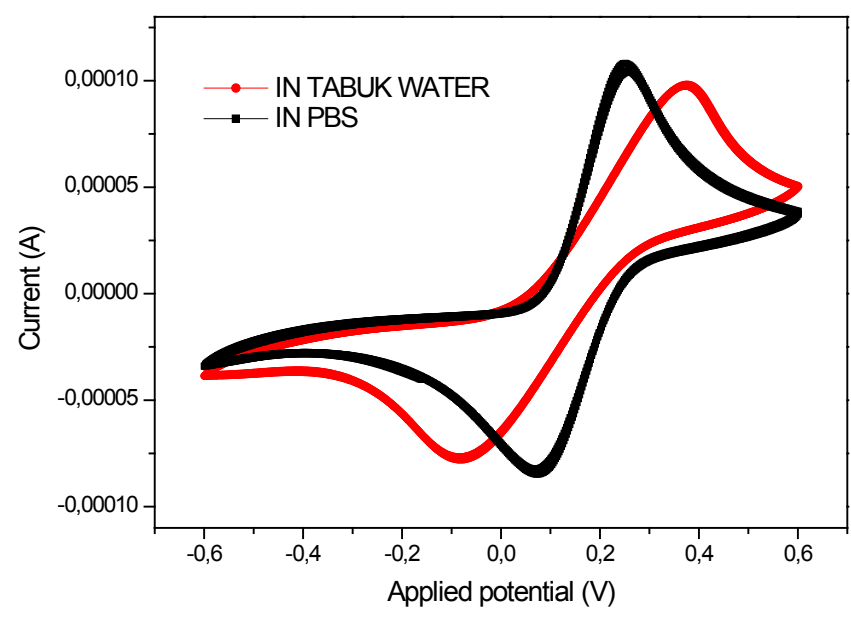

Figure 7: Cyclic voltammograms of the gold electrode, red, in PBS, black, in Tabuk water with redox. 
Citation: Helali S, Bohli N, Mostafa HMA, ben Zina H, Al-Hartomy OA, et al. (2016) Electrical Impedance Spectroscopy Using Single Wall Carbon Nanotubes Carboxlic Acid Functionalized: Detection of Copper in Tabuk-Kingdom of Saudi Arabia Water. J Nanomed Nanotechnol 7: 396. doi: 10.4172/2157-7439.1000396

Page 6 of 8

properties of the SWCNT-COOH layer which confirms success immobilization of the SWCNT-COOH.

Impedance spectroscopy: Figure 9 shows Nyquist plots for gold electrode in PBS and Tabuk water electrolyte at $200 \mathrm{mV}$ with redox couple, where $\mathrm{Z}_{\mathrm{re}}$ is the real part and $\mathrm{Z}_{\mathrm{im}}$ is the imaginary part of the complex impedance $Z$. Note that the spectra are almost similar. A typical shape of a impedance spectrum includes a semicircle region lying on the Zre-axis followed by a straight line. The semicircle portion, observed at higher frequencies, corresponds to the charge transfer resistance process, whereas the linear part is characteristic of the lower frequencies range and represents the diffusion process. The ohmic resistance Rs in high frequency ranges which is the resistance of the electrolyte was shifted from 250 to $650 \Omega$, this shows that Tabuk water conduct electricity less than PBS. This proves the Tabuk water hold a large number of matters.

\section{Copper detection}

The electrode modified with single wall carbon nanotubes functionalized with $\mathrm{COOH}$ was dipped into an electrochemical cell.

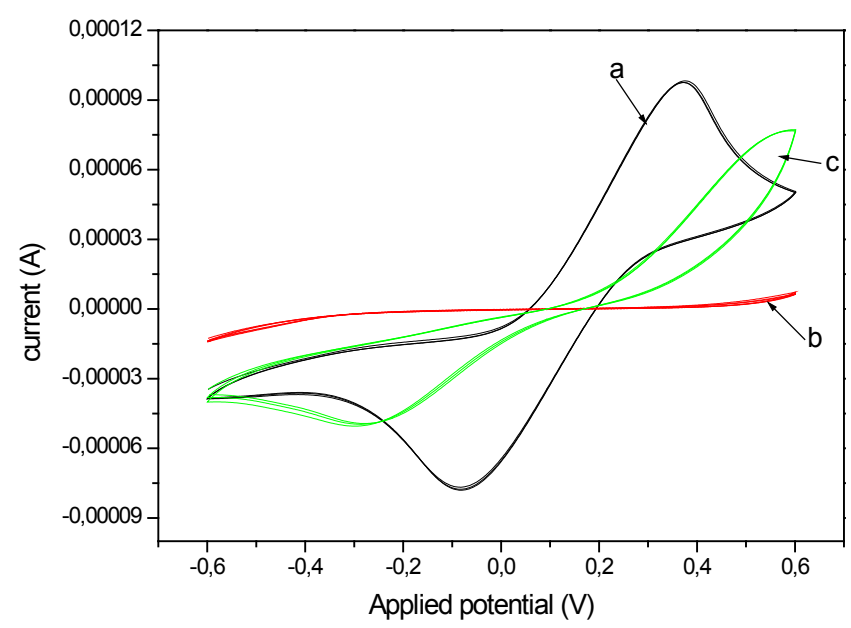

Figure 8: Cyclic voltammograms of (a) bare gold electrode, (b) SAM modified gold electrode (c) after SWCNTCOOH deposition with $100 \mathrm{mVS}^{-1}$ scan rate in Tabuk water with $5 \mathrm{mM} \mathrm{Fe}(\mathrm{CN})^{-4 /-3}$ solution.

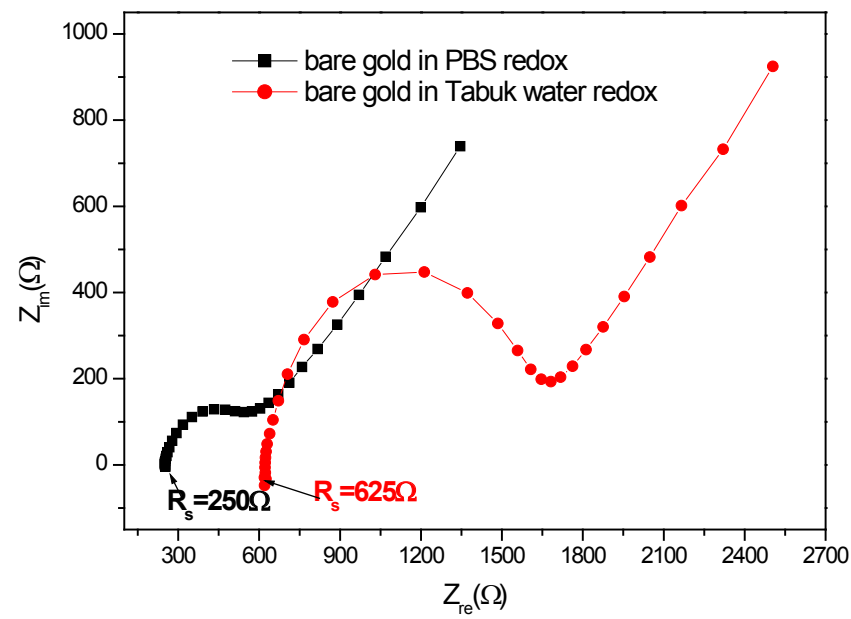

Figure 9: Nyquist diagram (Zre vs. Zim) for impedance measurements of the gold electrode, black, in PBS, red, in Tabuk water with redox.
Different volumes of copper corresponding to different concentrations were added into electrochemical cell at room temperature. CopperSWCNT-COOH interactions were monitored by impedance spectroscopy in PBS and in Tabuk water with redox couple. The impedance spectrum was measured for each calculated concentration of $\mathrm{Cu}(\mathrm{II})$ solution added, and after the impedance stabilization was achieved, a new concentration of $\mathrm{Cu}$ (II) was added to the cell. The impedance measurement results of copper in range of 0-300 ng/ $\mathrm{ml}$ are shown in Figure 10. Figure 10A shows the impedance spectra obtained after stabilization for different concentrations of copper in PBS and Figure 10B the impedance spectra in Tabuk water. The semicircle diameter in the Nyquist plot seems to increase with the copper concentration, implying that more amount of copper was linked to the interface for both electrolyte. When the concentration of copper was increased over $150 \mathrm{ng} / \mathrm{ml}$, the change of impedance spectroscopy become gradually weak shows that immobilization of the copper on a gold electrode trends to saturation situation.

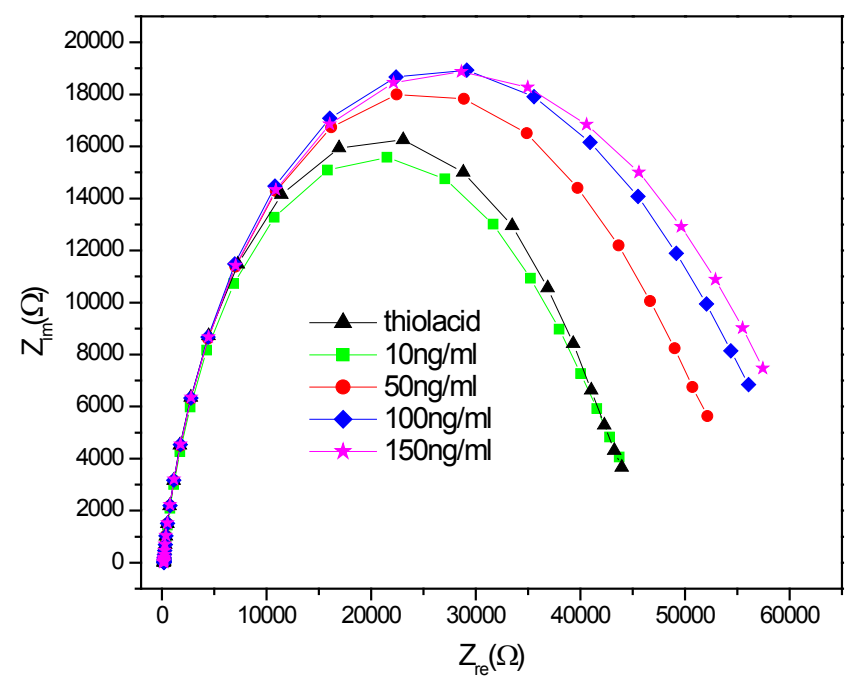

Figure 10A: Complex impedance plots of copper -SWCNTCOOH/SAM Au-electrode under various concentrations of copper. The concentrations of antigen (ng/ml): (a) 0; (b) 10; (c) 50; (d) 100 and (e) 150. Applied frequency from $0.05 \mathrm{~Hz}$ to $100 \mathrm{kHz}$ in PBS buffer.

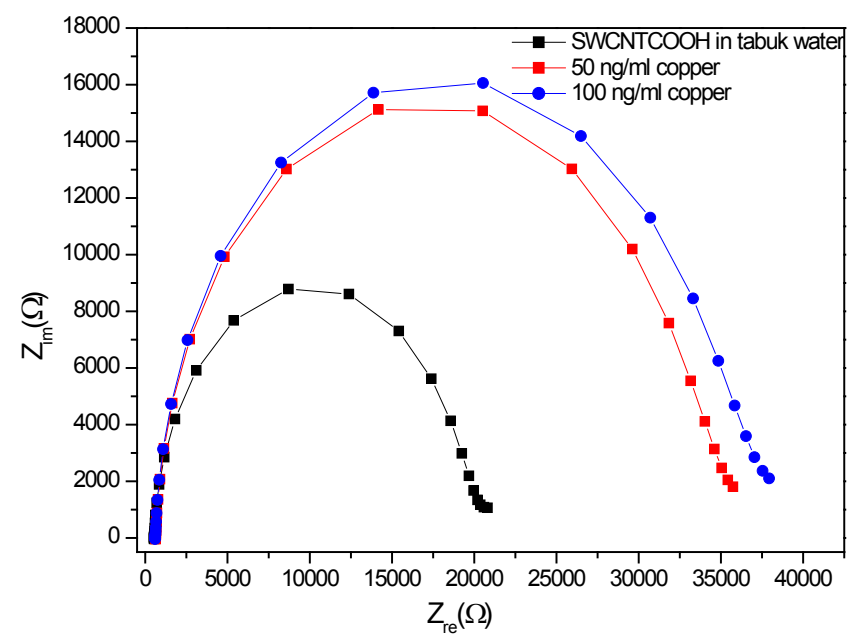

Figure 10B: Complex impedance plots of copper-SWCNTCOOH/SAM Au-electrode under various concentrations of copper. The concentrations of antigen (ng/ml): (a) 0; (b) 50; and (c) 100 in Tabuk water buffer. 
Citation: Helali S, Bohli N, Mostafa HMA, ben Zina H, Al-Hartomy OA, et al. (2016) Electrical Impedance Spectroscopy Using Single Wall Carbon Nanotubes Carboxlic Acid Functionalized: Detection of Copper in Tabuk-Kingdom of Saudi Arabia Water. J Nanomed Nanotechnol 7: 396. doi: 10.4172/2157-7439.1000396

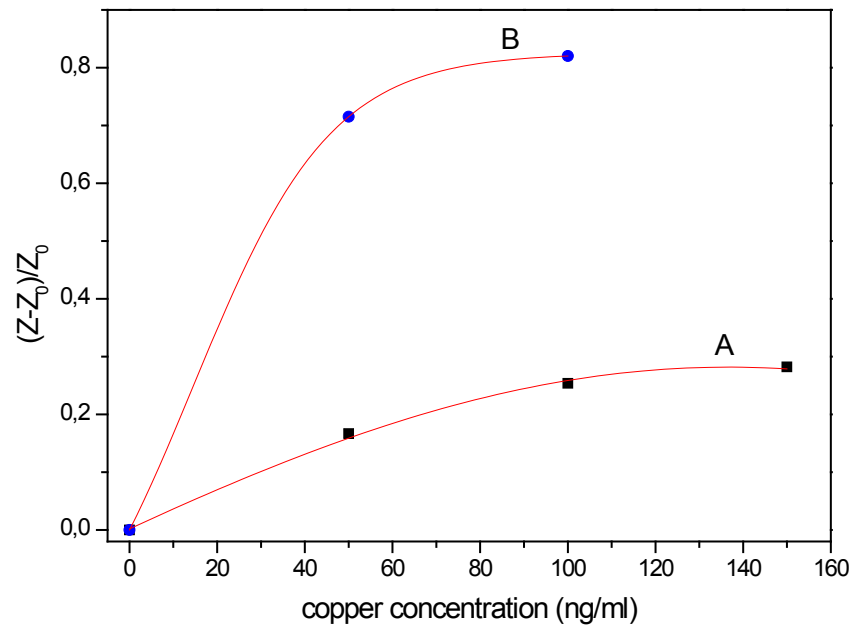

Figure 11: Average variation of $(Z-Z o) / Z_{0}$ at $156 \mathrm{mHz}$ versus copper concentration $(A)$ in PBS and $(B)$ in Tabuk water.

To illustrate the sensitivity of sensor response to substrate injection, corresponding to the average variation of $(\mathrm{Z}-\mathrm{Zo}) / Z_{0}$ at $156 \mathrm{mHz}$ versus copper concentration was plotted. $Z_{0}$ and $Z$ are respectively the total impedance of SWCNT-COOH layer and the impedance after copper injection. Figure 11 shows the calibration curves of the sensor exposed to different concentration of copper obtained from Figure 10. As can be seen in the figure, the signal in Tabuk water is four time large relative to the signal in PBS. These results prove that the Tabuk water contains a large proportion of copper.

\section{Conclusion}

This study gives us a new way to detect the copper in water using EIS. We used single-walled carbon nanotube carboxylic acid functionalized for copper detection. For carbon nanotubes immobilization, the gold electrode was activated over night with thiol-acid and then activated with EDC/NHS. Whereas, impedance spectroscopy was performed in order to monitor sensor architecture. The modified electrode was successfully tested in Tabuk water. The result proves that the Tabuk water contains a large proportion of copper. The response of the developed sensor shows that the signal in Tabuk water is four time large relative to the signal in PBS.

\section{Acknowledgements}

The authors would like to acknowledge financial support for this work , from the Deanship of Scientific Research (DSR), University of Tabuk, Saudi Arabia, under grand no S/1436/0281.

\section{References}

1. March G, Nguyen TD, Piro B (2015) Modified Electrodes Used for Electrochemical Detection of Metal lons in Environmental Analysis. Biosensors 5: 241-275.

2. Stafiej A, Pyrzynska K (2007) Adsorption of heavy metal ions with carbon nanotubes. Separation and Purification Technology 58: 49-52.

3. Fu F, Wang Q (2011) Removal of heavy metal ions from wastewaters: A review. Journal of Environmental Management 92: 407-418.

4. Turan NG, Mesci B (2011) Adsorption Of Copper (li) And Zinc (li) lons By Various Agricultural By-Products. Experimental Studies and Modelling Environment Protection Engineering 37: 143-161.

5. Yang Li, Helmreich B, Horn $\mathrm{H}$ (2011) Biosorption of $\mathrm{Cu}(\mathrm{II})$ lons from Aqueous Solution by Red Alga (Palmaria Palmata) and Beer Draff. Materials Sciences and Applications 2: 70-80.
6. Johnson PD, Watson MA, Brown J, Jefcoat IA (2002) Peanut hull pellets as a single use sorbent for the capture of $\mathrm{Cu}(\mathrm{II})$ from wastewater. Waste Manag 22 : 471-480.

7. Hsing IM, Xu Y, Zhao WT (2007) Micro and nano-magnetic particles for applications in biosensing. Electroanalysis 19: 755-768.

8. Fialova D, Kremplova M, Melichar L, Kopel P, Hynek D, et al. (2014) Interaction of Heavy Metal Ions with Carbon and Iron Based Particles. Materials 7: 2242-2256.

9. Kang I, Schulz MJ, Kim JH, Shanov V, Shi D (2006) A carbon nanotube strain sensor for structural health monitoring; Smart Mater. Struct. 15: 737-748

10. Mirfakhrai T, Oh J, Kozlov M, Fang S, Zhang M, et al. (2009) Carbon Nanotube Yarn Actuators: An Electrochemical Impedance Model. Journal of the Electrochemical Society 156: K97-K103

11. Cui L, Wu J, Ju H (2015) Electrochemical sensing of heavy metal ions with inorganic, organic and bio-materials. Biosensors and Bioelectronics 63: 276-286.

12. Hafaiedh I, Baccar H, Ktari T, Abdelghani A (2012) Electrochemical Characterization of Streptavidin-HRP Immobilized on Multiwall Carbon Nanotubes for Biosensor Applications. Journal of Biomaterials and Nanobiotechnology 3: 31-36

13. Dehghani $\mathrm{MH}$, Mostofi M, Alimohammadi M, McKay G, Yetilmezsoy $\mathrm{K}$, et al. (2015) High-performance removal of toxic phenol by single-walled and multiwalled carbon nanotubes: Kinetics, adsorption, mechanism and optimization studies. Journal of Industrial and Engineering Chemistry.

14. Kosaa SA, Al-Zhrania G, Salama MA (2012) Removal of heavy metals from aqueous solutions by multi-walled carbon nanotubes modified with 8-hydroxyquinoline. Chemical Engineering Journal 181: 159-168.

15. Marrakchi M, Helali S, Camino JS, González-Martínez MA, Abdelghani A, et al. (2013) Improvement of a pesticide immunosensor performance using sitedirected antibody immobilization and carbon nanotubes. Int J Nanotechnology 10: 496 - 507.

16. Ravelo-Perez LM, Hernández-Borges J, Ro- dríguez-Deigado MA ( 2008) Multi-Walled Carbon Nanotubes as Efficient Solid-Phase Extraction Materials of Organo- phosphorus Pesticides from Apple, Grape, Orange and Pineapple Fruit Juices. Journal of Chromatography A 1211: 33-42.

17. Tehrani MS, Azar PA, Namin PE, Dehaghi SE (2013) Removal of Lead Ions from Wastewater Using Functionalized Multiwalled Carbon Nanotubes with Tris(2-Aminoethyl)Amine. Journal of Environmental Protection 4: 529-536.

18. Cui L, Wu J, Ju HX (2015) Electrochemical sensing of heavy metal ions with inorganic, organic and bio-materials. Biosensors and Bioelectronics 63: 276-286.

19. Ibrahim S, Yasin SMM, Ng MN, Ahmad R, Johan MR (2011) Impedance spectroscopy of carbon nanotube/solid polymer electrolyte composites. Solid State Communications 151: 1828-1832.

20. Farma R, Deraman M, Awitdrus, Talib IA, Omar R, et al. (2013) Physical and Electrochemical Properties of Supercapacitor Electrodes Derived from Carbon Nanotube and Biomass Carbon. Int J Electrochem Sci 8: 257-273.

21. Hafaiedh I, Ameur S, Abdelghani A (2012) Impedance Spectroscopy of Supported Multiwalled Carbon Nanotubes for Immunosensor Applications. J Nanomedic Nanotechnol.

22. Silva MG, Helali S, Esseghaier C, Suarez CE, Oliva A, et al. (2008) An impedance spectroscopy method for the detection and evaluation of Babesia bovis antibodies in cattle. Sensors and Actuators B Chemical 135: 206-213.

23. Esseghaier C, Helali S, Fredj HB, Tlili A, Abdelghani A (2008) Polypyrroleneutravidin layer for impedimetric biosensor. Sensors and Actuators B. Chemical 131: 584-589.

24. Hnaien M, Diouani MF, Helali S, Hafaid I, Hassen WM, et al. (2008) Immobilization of specific antibody on SAM functionalized gold electrode fo rabies virus detection by electrochemical impedance spectroscopy. Biochemical Engineering Journle 39: 443-449.

25. Diouani MF, Helali S, Hafaid I, Hassen WM, Snoussi MA, et al. (2008) Miniaturized biosensor for avian influenza virus detection. Materials Science and Engineering C 28: 580-583.

26. Fredj HB, Helali S, Esseghaier C, Vonna L, Vidal L, et al. (2008) Labeled Magnetic Nanoparticles Assembly on Polypyrrole Film for Biosensor Applications. Talanta 75: 740-747. 
Citation: Helali S, Bohli N, Mostafa HMA, ben Zina H, Al-Hartomy OA, et al. (2016) Electrical Impedance Spectroscopy Using Single Wall Carbon Nanotubes Carboxlic Acid Functionalized: Detection of Copper in Tabuk-Kingdom of Saudi Arabia Water. J Nanomed Nanotechnol 7: 396. doi: 10.4172/2157-7439.1000396

Page 8 of 8

27. Bouafsoun A, Helali S, Mebarek S, Zeiller C, Prigent A, et al. (2007) Electrical probing of endothelial cell behaviour on a fibronectin/polystyrene/thiol/ gold electrode by Faradaic electrochemical impedance spectroscopy (EIS). Bioelectrochemistry 70: 401-407.

28. Tlili A, Abdelghani A, Hleli S, Maaref MA (2004) Electrical Characterization of a Thiol SAM on Gold as a First Step for the Fabrication of Immunosensors based on a Quartz Crystal Microbalance. Sensors 4: 105-114.

29. Kouklin N, Tzolov M, Straus D, Xu JM (2004) Infrared absorption properties of carbon nanotubes synthesized by chemical vapor deposition. Applied Physics Letters 85: 4463

30. Hafaiedh I, Baccar H, Ktari T, Abdelghani A ( 2012) Electrochemical Characterization of Streptavidin-HRP Immobilized on Multiwall Carbon
Nanotubes for Biosensor Applications. Journal of Biomaterials and Nanobiotechnology 3: 31-36.

31. Wiegand (1999) Fundamental principles of the electric properties of supported lipid membranes investigated by advanced methods of impedance spectroscopy, Shaker verlag, ISBN 3-8265-7231-9, Technishe Universitat of Muenchen, Germany.

32. MacDonald R (1987) Impedance Spectroscopy, Wiley, New York, USA.

33. Gadhave A, Waghmare J (2014) Removal of Heavy Metal lons From Wastewater By Carbon Nanotubes (CNTs). International Journal of Chemical Sciences and Applications 5: 56-67.

34. Sakthivel S, Kisch H (2003) Daylight photocatalysis by carbon-modified titanium dioxide. Angew Chem Int Ed Engl 42: 4908-4911. 